\title{
Low birth weight in Jordan: a hospital-based study
}

\author{
Khitam Mohammed ${ }^{a}$, Insaf Shaban ${ }^{b}$, Nemeh Al-Akour ${ }^{c}$, Manal Kassab $^{c}$ and Debra Creedy ${ }^{d}$ \\ ${ }^{a}$ Maternal and Child Health and Midwifery Department, Jordan University of Science and Technology, Irbid, Jordan; ${ }^{b}$ Maternal and \\ Child Health Department, Al al-Bayt University Princess Salma Faculty of Nursing, Mafraq, Jordan; 'Maternal and Child Health

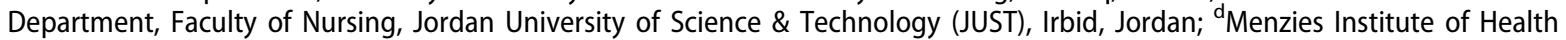 \\ Queensland, Griffith University, Brisbane, Australia
}

ABSTRACT

Background: Low birth weight (LBW) is one of the leading causes of neonatal and infant morbidity and mortality.

Objective: To determine the prevalence and possible risk factors associated with LBW in four regional hospitals in Jordan.

Methods: This retrospective study analyzed the medical records of all singleton live births for the period 2011-2015.

Results: A total of 22,789 singleton live births were included for this study. Of these, 4133 (18\%) had a LBW. Rates of LBW increased over the 5 years study period. Factors associated with LBW were preterm birth, pregnancy complications or comorbidities, older maternal age $(\geq 35$ years), first-born infants, and having a female baby.

Conclusion: Midwives' assessment and health education messages to mothers included awareness of risk factors associated with LBW of neonates in Jordan. Effective public health interventions need to highlight the importance of a healthy diet and valuing female off-spring.
ARTICLE HISTORY

Received 21 September 2018

Revised 10 December 2018

Accepted 7 January 2019

\section{KEYWORDS}

Jordan; low birth weight; retrospective chart audit; risk factors

\section{Introduction}

Birth weight is a good indicator of maternal and neonatal nutritional status, and contributes to newborn survival, growth, long-term health, and psychosocial development $[1,2]$. Low birth weight (LBW) is defined as "birth weight less than $2500 \mathrm{~g}$ " [3]. LBW is commonly due to intrauterine growth retardation, preterm birth (babies born alive before 37 weeks of pregnancy), or a combination of both $[4,5]$. Worldwide, more than 20 million LBW babies $15.5 \%$ of total births) are born every year, with around 95\% from developing countries [4-6]. The prevalence of LBW in developing countries is estimated to be $19 \%$, compared to $5-7 \%$ in developed countries $[6,7]$. The incidence of LBW has not decreased in the last decade in Asia and Sub-Saharan Africa [8].

LBW is one of the leading causes of neonatal and infant morbidity and mortality $[1,5,7,9]$. It contributes to about $75 \%$ of deaths in the first week of life $[4,6]$. Extensive research confirms that LBW infants are at greater risk for developmental delays and increased medical care costs $[4,8,10]$. LBW infants experience health and learning problems of different types, which can negatively impact their physical, cognitive, and mental well-being $[1,4,7]$. Lifelong health problems related to LBW include adult-onset diabetes, coronary heart disease, hypertension, intellectual, physical and sensory disabilities, and psychological distress $[1,4,6,11,12]$.

Risk factors associated with having a LBW baby include being an adolescent or older mother $(>35$ years of age), low socioeconomic status, low educational level, first time mothers, pregnancy complications and comorbidities (such as anemia oligohydramnios, abruptio placenta, placenta previa, hypertensive disorders during pregnancy), poor diet and/or lifestyle choices during pregnancy, having a female baby, multiple gestation, maternal smoking, psychosocial stress, and insufficient antenatal care $[1,6,7,10-12]$.

While LBW trends and associated factors are wellresearched in developed countries, there is insufficient published evidence from developing countries [10]. The prevalence of LBW in a global study reported that rates in Jordan had increased from $8.8 \%$ in 1990 to $10.2 \%$ in 2002 , and $19.6 \%$ in 2012 [1]. LBW accounted

CONTACT Khitam Mohammed mohammad211003@yahoo.com @ Maternal and Child Health and Midwifery Department, Jordan University of Science and Technology, Irbid, Jordan

(C) 2019 Informa UK Limited, trading as Taylor \& Francis Group 
for $4.6 \%$ of all infant deaths in Jordan and is one of the leading causes of neonatal death [13]. In Jordan, a retrospective study by Mohammad et al. [14] aimed to determine the impact of social factors on birth weight (normal, low, and over birth weight) of 5414 full-term singleton babies born in 2010. The authors found that mean birth weight was lower in first born or female babies, older mothers ( $>35$ years), low monthly income $(<500$ Jordanian dinar), and low maternal educational level.

To date, no study has been conducted either in Jordan or any of the Arab countries to investigate trends and factors associated with LBW. This study investigated the trends in prevalence and medicosocial risk factors contributing to LBW in Northern Jordan over a period of 5 years (2011-2015).

\section{Materials and methods}

\section{Settings}

This retrospective study investigated all singleton live birth records over a 5-year period (2011-2015) in four government-funded hospitals in Irbid governorate of Jordan. Irbid governorate is located in the north of Jordan. It has the second largest population in the country and the highest population density in Jordan. Irbid governorate has a population of $1,770,158$. The study was conducted in four government-funded hospitals. Princess Badea Teaching Hospital for Obstetrics and Gynecology is the biggest hospital in the central of the governorate with an annual birth rate of 8816 . Al-Ramtha hospital located in the north-east of the Irbid governorate has an annual birth rate of 1982. AlYarmouk hospital in the north has an annual birth rate of 1075, and Princess Raya hospital in the west has an annual birth rate of 1520 [15]. Collectively, these hospitals provide birthing services for around 14,000 women per year and offer different levels of maternity services. Any complicated and high-risk cases are usually transferred to the Princess Badea Teaching Hospital, which is a tertiary facility. Cesarean section rates in the Princess Badea Teaching Hospital are higher (44.6\%) than those reported in the other three hospitals (Al-Ramtham 15.6\%, Al-Yarmouk 22\%, Princess Raya 19.7\%) [15].

\section{Data source}

In the current study, cases were identified by searching maternal health records for all singleton live births during the study period. Multiple and stillbirths during the study period were excluded. Extracted maternal information included maternal age $(<25$ years, $25-34$ years, $\geq 35$ years); educational level (high school or less, diploma, bachelor or more); parity (number of children); and occurrence of pregnancy comorbidities and complications such as anemia, oligohydramnios, abruptio placenta, placenta previa, and hypertensive disorders during pregnancy (yes, no). Newborn information included gender (male, female), gestational age which was defined as the number of weeks of pregnancy and classified into two categories $(<37-$ week gestation (preterm) and $\geq 37$-week gestation (term)), and birth weight (grams). Maternal health records with missing values for any study variables were disregarded. Mothers who birthed more than once in the survey period were also excluded, as shown in Figure 1.

\section{Statistical analysis}

Data analysis was performed with SPSS version 22 . Collected data were cleaned and reviewed for completeness and consistency both within a single data form and among different data forms. Frequencies, means, and standard deviations were calculated as appropriate on the maternal and neonatal variables. To examine relationships between study variables and LBW, a multivariate, stepwise regression analysis was conducted. The relative contribution of each factor to LBW was explained using the coefficient of determination $\left(R^{2}\right)$ from the multivariate model. An alpha level of 0.05 was used for all statistical tests.

\section{Ethical considerations}

The study was approved by the Institutional Review Board at Jordan University of Science and Technology and the Ministry of Health in Jordan.

\section{Results}

A total of 22,789 singleton live births occurred during the study period, of which 4133 were LBW infants $(<2500 \mathrm{~g})$. Prevalence of LBW in the current study period increased from $16.6 \%$ in 2011 to $19.2 \%$ in 2015. Table 1 presents the distribution of newborn birth weights over the study period. Prevalence of LBW over the study period (5 years) was estimated at $18 \%$. Mean LBW for newborns was $2048.85 \mathrm{~g}$. Maternal and neonatal characteristics are presented in Table 2 .

The best multivariate model associated with LBW included preterm birth, maternal complications during pregnancy, infants of older mothers, first born, and 


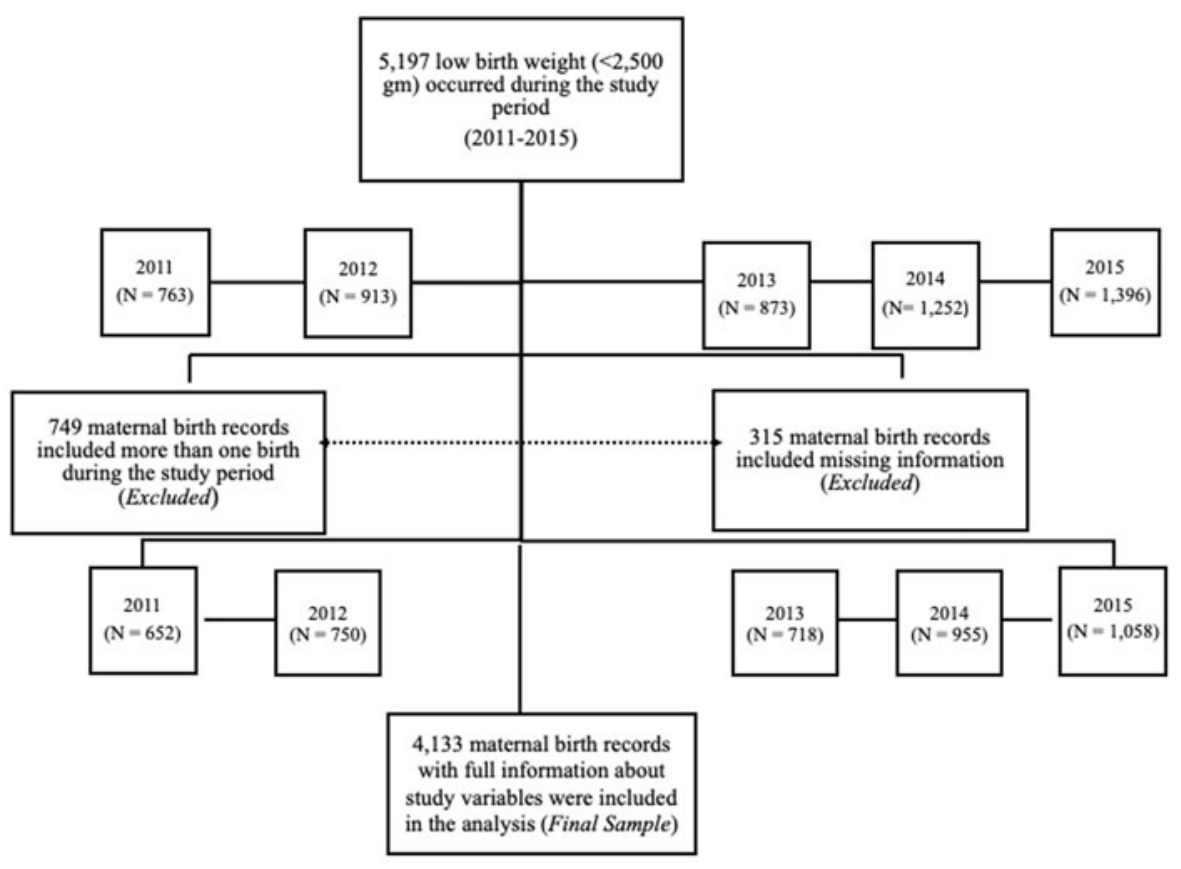

Figure 1. Sample selection.

Table 1. Distribution of newborn birth weights 2011-2015.

\begin{tabular}{|c|c|c|c|c|c|c|c|c|c|}
\hline & \multirow[b]{2}{*}{ Total } & \multirow[b]{2}{*}{$>2.5$} & \multirow[b]{2}{*}{$<2.5$} & \multirow[b]{2}{*}{ Percentage $(>2.5)$} & \multirow[b]{2}{*}{ Percentage $(<2.5)$} & \multicolumn{2}{|c|}{$\begin{array}{c}95 \% \\
\text { confidence } \\
\text { interval }\end{array}$} & \multirow[b]{2}{*}{ Chi- square } & \multirow[b]{2}{*}{ Sig. ( $p$-value } \\
\hline & & & & & & Lower & Upper & & \\
\hline 2011 & 3926 & 3274 & 652 & 83.4 & 16.6 & 82.23 & 84.56 & 1751.12 & $<.001$ \\
\hline 2012 & 4335 & 3585 & 750 & 82.7 & 17.3 & 81.57 & 83.82 & 1854.03 & $<.001$ \\
\hline 2013 & 3967 & 3249 & 718 & 81.9 & 18.1 & 80.70 & 83.10 & 1614.81 & $<.001$ \\
\hline 2014 & 5053 & 4098 & 955 & 81.1 & 18.9 & 80.02 & 82.18 & 1954.97 & $<.001$ \\
\hline 2015 & 5508 & 4450 & 1058 & 80.8 & 19.2 & 79.75 & 81.83 & 2088.90 & $<.001$ \\
\hline Total & 22,789 & 18,656 & 4133 & 81.9 & 18.1 & 81.36 & 82.36 & 9255.23 & $<.001$ \\
\hline
\end{tabular}

Table 2. Maternal and neonatal characteristics.

\begin{tabular}{|c|c|c|}
\hline Demographic characteristics & $N=365$ & $(\%)$ \\
\hline \multicolumn{3}{|l|}{ Mothers' age } \\
\hline Less than 25 years & 1412 & 34.1 \\
\hline $25-34$ years & 1643 & 39.8 \\
\hline More than 34 years & 1078 & 26.1 \\
\hline \multicolumn{3}{|l|}{ Mothers' educational level } \\
\hline High school or less & 1355 & 32.8 \\
\hline Diploma & 1895 & 45.8 \\
\hline Bachelor or more & 883 & 21.4 \\
\hline \multicolumn{3}{|l|}{ Parity } \\
\hline 1 child & 1825 & 44.2 \\
\hline 2-3 children & 1457 & 35.3 \\
\hline 4 children or more & 851 & 20.6 \\
\hline \multicolumn{3}{|c|}{ Occurrence of pregnancy comorbidities and/or complications } \\
\hline Yes & 1370 & 33.1 \\
\hline No & 2763 & 66.9 \\
\hline \multicolumn{3}{|l|}{ Sex of baby } \\
\hline Male & 2122 & 51.3 \\
\hline Female & 2011 & 48.7 \\
\hline \multicolumn{3}{|l|}{ Gestational age } \\
\hline$<37$-week gestation (preterm) & 2312 & 55.9 \\
\hline$\geq 37$-week gestation (term) & 1821 & 44.1 \\
\hline \multicolumn{3}{|l|}{ Mode of birth } \\
\hline Normal vaginal birth & 2736 & 66.2 \\
\hline Cesarean section & 1397 & 33.8 \\
\hline \multicolumn{3}{|l|}{ Place of residence } \\
\hline Urban area & 1824 & 44.1 \\
\hline Rural area & 2309 & 55.9 \\
\hline
\end{tabular}

female infants (as shown in Table 3). This multivariate model predicted $51 \%$ of the variance. Being born preterm was the strongest factor associated with LBW $\left(R^{2}=0.27\right)$ followed by infants of mothers who experienced complications during pregnancy.

\section{Discussion}

The current study investigated trends and factors associated with LBW in four hospitals in Jordan over 5 years. The current study estimated the prevalence of LBW $(<2500 \mathrm{~g})$ infants to be $18 \%$, which is similar to other studies in developing countries such as Yamen (18\%) and Zimbabwe (16.7\%) [1,16]. The prevalence was, however, much lower than some other developing countries such as Ghana (26.1\%) and India (27.1\%) [17-19]. Our estimation of LBW was higher than the rate of $12.8 \%$ reported by Mohammad et al. [14] in 2010 in Jordan as well as similar countries such as 
Table 3. Multivariate linear model (stepwise stepping procedure) for differences in mean LBW of newborn babies.

\begin{tabular}{|c|c|c|c|c|c|c|c|}
\hline \multirow[b]{2}{*}{ Variable } & \multicolumn{2}{|c|}{$\begin{array}{l}\text { Unstandardized } \\
\text { coefficients }\end{array}$} & \multirow{2}{*}{$\begin{array}{c}\begin{array}{c}\text { Standardized } \\
\text { coefficients }\end{array} \\
\text { Beta }\end{array}$} & \multirow[b]{2}{*}{$p$} & \multirow[b]{2}{*}{ Partial $R^{2}$} & \multicolumn{2}{|c|}{ 95\% Confidence interval for B } \\
\hline & B & Std. Error & & & & Lower bound & Upper bound \\
\hline Preterm babies* & 294.33 & 18.90 & 0.25 & $<.001$ & 0.27 & 257.28 & 331.38 \\
\hline $\begin{array}{l}\text { Occurrence of pregnancy } \\
\text { comorbidities and/or } \\
\text { complications }\end{array}$ & 172.29 & 19.27 & 0.14 & $<.001$ & 0.11 & 134.51 & 210.08 \\
\hline Older mothers ( $\geq 35$ years) & 89.75 & 12.56 & 0.12 & $<.001$ & 0.08 & 65.13 & 114.37 \\
\hline First born infant & 51.56 & 12.01 & 0.07 & $<.001$ & 0.04 & 28.02 & 75.10 \\
\hline Female baby & 17.46 & 11.28 & 0.05 & .001 & 0.01 & 21.17 & 32.49 \\
\hline
\end{tabular}

*Preterm babies $=$ babies born alive before 37 weeks of pregnancy.

Pakistan (10\%), Ethiopia (10.5\%), Iran (9.4\%), and Oman (9\%) $[6,7,20,21]$.

The differences in rates of LBW between countries might be related to a number of factors. In Jordan, most births $(99 \%)$ occur primarily in public sector facilities, which may not be the case in other developing countries. Jordan has developed a well-organized health information system which can be used to capture and interpret trends in the incidence of LBW, which may also differ from other developing countries. There is a high level of obstetric intervention in Jordan, and many preterm births are a result of early induction of labour or cesarean section (CS). The CS rate has increased from 19\% in 2007 to $28 \%$ in 2012 [22]. This rising trend in CS and the possible association with rising rates of LBW in Jordan needs to be given special attention by healthcare services to reduce unnecessary obstetric intervention.

The present study showed that factors correlated with LBW included preterm birth, older maternal age, parity, and pregnancy comorbidities and complications. This is consistent with the results of some previous studies $[1,7,9,21]$. In most studies, preterm birth is reported as a dominant risk factor for LBW $[7,9,17,21]$. Greater attention to maternal diet, better health education, and a reduction in obstetric intervention may all contribute to reducing preterm births.

Results of this study showed older mothers were at risk for having a LBW infant. This may be related to the increasing number of women marrying and commencing their childbearing later. The mean age at marriage for females in Jordan has increased from 23 years in 2010 to 29 years in 2016 [23]. With couples marrying later in life, more women are choosing to have children at the age of 35 years and older. As older mothers are at greater risk for certain complications during pregnancy that may require a CS, these social changes may be simultaneously contributing to an increase in LBW. Researchers have shown that the occurrence of perinatal complications among pregnant women of advanced age is significantly higher than among younger women $[1,21,24-26]$.

The findings of the current study also revealed that pregnant women with pregnancy comorbidities and/ or complications were more likely to give birth to LBW babies than those without such comorbidities and complications. If the complications progress in pregnancy or fetal distress becomes apparent, then preterm births are more likely $[9,21,27]$. According to the World Bank [28], 35\% of Jordanian women suffer from anemia which may be associated with diet and frequent childbearing. Furthermore, research on smoking (active and passive) and birth outcomes have found a high prevalence of smoking among males (50\%) in Jordan [29]. High hematocrit is linked to hypertensive conditions in pregnancy, and smoking increases the risk for preeclampsia, placenta previa, and abruption placenta $[9,21]$. Current findings highlight that active prevention, early diagnosis, and timely management of obstetric comorbidities and complications are especially important.

In this study, being a first-born infant was identified as a risk factor. It is well-recognized that second and third babies weigh more than the first [25]; however, the risk of LBW again increases with the fourth and subsequent babies [25]. The findings of this study are similar to most previous studies [4-6,19,21,30]. Our findings suggest that primiparous women may not have enough knowledge to plan their diet to minimize risks and ensure a healthy birthweight of their newborn babies.

The current study found an association between female infants and LBW, which is consistent with previous studies $[6,7,9,11,12,16]$. One Jordanian study reported that women who knew that they were pregnant with a male baby tended to have significantly more antenatal visits than women pregnant with female baby [31]. This may be related to the fact that most Jordanian families continue to prefer males over females, as a son continues the family name, contributes to the financial well-being of the family, and 
retains family loyalty [14,32]. Women who are pregnant with a female baby may ignore their health, not maintain a healthy diet, or adopt unhealthy lifestyle habits. All of these factors may contribute to LBW infants. Educating pregnant women about the risks and consequences of LBW on the immediate and long-term health of their newborn may reduce the prevalence of LBW in Jordan.

No significant association was observed between the maternal level of education and LBW, which is consistent with the results of some previous studies $[6,19]$. It could be that many women in Jordan are now receiving more education. Although some studies suggest an association between lower levels of maternal education and LBW $[1,12,21,26]$, this was not evident in the current study.

\section{Conclusion}

Despite universal health care services provided via a public network system in Jordan, the mean national prevalence of LBW is still high. In order to reduce preterm birth rates, educational interventions for high-risk groups are required especially for older women ( $>35$ years). Furthermore, family planning education and support are needed to help women achieve appropriate interpregnancy intervals, maintain proper nutrition during pregnancy and reduce factors contributing to high-risk pregnancies.

\section{Limitations}

The present study has several limitations that need to be acknowledged. The findings can only be generalized to singleton live pregnancies in governmentfunded hospitals in Jordan, where they provide care for women with low and high obstetric risk. In addition, these hospitals provide care for women of low or moderate income and for those who have government-funded health care insurance. While the findings of this study are applicable to singleton live pregnancies in countries who share similar cultural and traditional values as Jordan, health care delivery may vary. Due to the data collection methods, some influential characteristics of pregnancy, such as the weight of mother, number of prenatal care visits, and total family income were not available, but should be sought in future research if possible.

\section{Implications for practice}

The findings of the current study inform our understanding of some factors affecting LBW of neonates in
Jordan. Although there are widespread health care and good reporting systems in the country, changes in maternity practice have been slow to follow best available evidence. Awareness of risk factors for LBW infants by midwives and nurses will enable at-risk mothers to be identified, receive early interventions such as iron and folate supplements, and receive health education about diet and family planning. The government needs to encourage continuity of midwifery care for all women and a reduction in unnecessary obstetric procedures (such as CS). The development of effective public health interventions for at-risk mothers need to be considered, especially around cultural issues that value the contribution of women to Jordanian society.

\section{Disclosure statement}

No potential conflict of interest was reported by the authors.

\section{References}

[1] Mahumud RA, Sultana M, Sarker AR. Distribution and determinants of low birth weight in developing countries. JPMPH. 2017;50:18-28.

[2] Pei L, Kang Y, Zhao Y, et al. Changes in socioeconomic inequality of low birth weight and macrosomia in Shaanxi Province of Northwest China, 2010-2013. A cross-sectional study. Med Baltimore. 2016;95: e2471.

[3] World Health Organization [Internet]. World health statistics 2010; 2010 [cited 2018 Aug 21]. Available from: www.who.int/gho/publications/world_health statistics/EN_WHS10_Full.pdf.

[4] Agbozo F, Abubakari A, Der J, et al. Prevalence of low birth weight, macrosomia and stillbirth and their relationship to associated maternal risk factors in Hohoe Municipality, Ghana. Midwifery. 2016;40:200-206

[5] Ahankari A, Bapat S, Myles P, et al. Factors associated with preterm delivery and low birth weight: a study from rural Maharashtra, India. F1000Research. 2017;6:72.

[6] Iltaf G, Shahid B, Khan MI. Incidence and associated risk factors of low birth weight babies born in Shaikh Khalifa Bin Zayad Al-Nayan Hospital Muzaffarabad, Azad Jammu and Kashmir. Pak J Med Sci. 2017;33: 626-630.

[7] Mengesha HG, Wuneh AD, Weldearegawi B, et al. Low birth weight and macrosomia in Tigray, Northern Ethiopia: who are the mothers at risk? BMC Pediatr. 2017;17:144.

[8] Kayode GA, Amoakoh-Coleman M, Agyepong IA, et al. Contextual risk factors for low birth weight: a multilevel analysis. PLoS One. 2014;9:e109333.

[9] Mitao M, Philemon R, Obure J, et al. Risk factors and adverse perinatal outcome associated with low birth weight in Northern Tanzania: a registry-based 
retrospective cohort study. Asian Pac J Reprod. 2016; 5:75-79.

[10] Islam MM. Increasing incidence of infants with low birth weight in Oman. Sultan Qaboos Univ Med J. 2015;15:e177-e183.

[11] Beddek F, Demmouche A, Mai AH, et al. Low birth weight in Sidi Bel Abbès Region (West of Algeria): retrospective study of 10008 deliveries. J Blood Disord Transfus. 2014;5:210.

[12] Bhattacharjya H, Das S, Ghosh D. Proportion of low birth weight and related factors in a tertiary care institute of Tripura. Int J Med Public Health. 2015;5(1): 10-13.

[13] Obeidat N, Khader Y, Batieha A, et al. Neonatal mortality in Jordan: secondary analysis of Jordan Population and Family Health Survey (JPFHS) data. J Matern Fetal Neonatal Med. 2019;32:217-224.

[14] Mohammad K, Kassab M, Gamble J, et al. Factors associated with birth weight inequalities in Jordan. Int Nurs Rev. 2014;1111:435-440.

[15] The Hashemite Kingdom of Jordan Ministry of Health. Ministry of Health annual statistical Report 2017; 2017 [cited 2018 Dec 2]. Available from: http://www.moh.gov.jo/Echobusv3.0/.../17e34eb7-545d-4a00-ab72c391859aa58b.pdf

[16] Feresu SA, Harlow SD, Woelk GB. Risk factors for low birthweight in Zimbabwean women: a secondary data analysis. PLoS One. 2015;10:e0129705.

[17] Abubakari A, Kynast-Wolf G, Jahn A. Maternal determinants of birth weight in Northern Ghana. PLoS One. 2015;10:e0135641.

[18] Jalil A, Usman A, Rubeena Z. Maternal factors determining low birth weight in Punjab: a secondary data analysis. FWU J Soc Sci. 2016;10:70-79.

[19] Lateef E, Gupta P, Srivastava JP. The prevalence of low birth weight infants amongst hospital deliveries in Lucknow. Int J Community Med Public Health. 2017;2:510-512.

[20] Islam MM, Elsayed MK. Pattern and determinants of birth weight in Oman. Public Health. 2015;129: 1618-1626.

[21] Momeni M, Danaei M, Kermani AJ, et al. Prevalence and risk factors of low birth weight in the Southeast of Iran. Int J Prev Med. 2017;8:12.
[22] Department of Statistics. [Jordan] and ICF International [Internet]. Jordan population and Family Health survey 2012. Calverton, MD: Department of Statistics and ICF International; 2013 [cited 2018 Aug 26]. Available from: http://dhsprogram.com/pubs/pdf/ FR282/FR282.pdf.

[23] Department of Statistics. [Jordan] [Internet]. Jordan statistical yearbook, 67th Issue. Jordan; 2016. Available from: dosweb.dos.gov.jo/DataBank/yearbook/YearBook2016_eng.pdf.

[24] Bener A, Salameh KM, Yousafzai MT, et al. Pattern of maternal complications and low birth weight: associated risk factors among highly endogamous women. ISRN Obstet Gynecol. 2012;2012:540495.

[25] Chaman R, Amiri M, Raei $M$, et al. Low birth weight and its related risk factors in Northeast Iran. Iran J Pediatr. 2013;23:701-704.

[26] Mahumud RA, Sarker AR, Sultana $M$, et al. Prevalence and associated determinants of low birth weight in developing countries: a multi-country analysis from nationwide population-based survey. In: De U, Pal M, Bharati $P$, editors. Issues on health and healthcare in India. Singapore: Springer; 2018. p. 21-40.

[27] Ricci SS. Essentials of maternity, newborn, and women's health nursing. 4th ed. New York (NY): Wolters Kluwer; 2017.

[28] The World Bank [Internet]. Prevalence of anemia among non-pregnant women (\% of women ages 15-49); 2018 [cited 2018 Aug 23]. Available from: https://data.worldbank.org/indicator/SH.ANM.NPRG.ZS.

[29] Abu-Baker NN, Haddad L, Savage C. The influence of secondhand smoke exposure on birth outcomes in Jordan. Int J Environ Res Public Health. 2010;7: 616-634.

[30] Shuaib A, Frass KA. Occurrence and risk factors of low birth weight in Sana'a, Yemen. J High Instit Public Health. 2017;47:8-12.

[31] Al-Akour NA. Knowing the fetal gender and its relationship to seeking prenatal care: results from Jordan. Matern Child Health J. 2008;12:787-792.

[32] Mohammad KI, Gamble J, Creedy DK. Prevalence and factors associated with the development of antenatal and postnatal depression among Jordanian women. Midwifery. 2011;27:e238-e245. 


\section{The Journal of Maternal-Fetal \& Neonatal Medicine}

ISSN: 1476-7058 (Print) 1476-4954 (Online) Journal homepage: https://www.tandfonline.com/loi/ijmf20

\section{Low birth weight in Jordan: a hospital-based study}

Khitam Mohammed, Insaf Shaban, Nemeh Al-Akour, Manal Kassab \& Debra Creedy

To cite this article: Khitam Mohammed, Insaf Shaban, Nemeh Al-Akour, Manal Kassab \& Debra Creedy (2019): Low birth weight in Jordan: a hospital-based study, The Journal of Maternal-Fetal \& Neonatal Medicine, DOI: 10.1080/14767058.2019.1567707

To link to this article: https://doi.org/10.1080/14767058.2019.1567707

Accepted author version posted online: 08

Jan 2019.

Published online: 17 Jan 2019.

Submit your article to this journal $₫$

山 Article views: 45

View Crossmark data ¿ 